\title{
Cerebral Venous Sinus Thrombosis Masquerading as High Altitude Cerebral Edema at Extreme Altitude
}

\author{
Inam Danish Khan* \\ Clinical Microbiology, Army College of Medical Sciences and Base Hospital, Delhi Cantt 110010, India
}

Corresponding Author: Inam Danish Khan, MBBS, MD, DNB, Assistant Professor, Clinical Microbiology, Army College of Medical Sciences and Base Hospital, Delhi Cantt 110010, India. Tel: +91-9836569777, Fax: +91-11-25693490, Email: titan_afmc@yahoo.com

Received June 17, 2016; Accepted July 5, 2016; Online Published September 25, 2016

\begin{abstract}
Introduction: Extreme altitude travel has gained popularity globally for adventurous, scientific, and military endeavors. Cerebral venous sinus thrombosis (CVST) at extreme altitude is a rare, covert, and emergent condition requiring immediate intervention.

Case Presentation: A case of CVST masqueraded as high altitude cerebral edema (HACE) at $6700 \mathrm{~m} / 22000 \mathrm{ft}$ in Karakoram Himalayas. Atypical oligosymptomatic presentation along with terrain, weather, and communication restrictions complicated diagnosis and management, leading to demise. CVST, confirmed on autopsy, was not associated with any pre-existing risk factors. Conclusion: CVST at extreme altitude can occur spontaneously due to prolonged hypobaric hypoxia which can precipitate thrombosis through capillary damage, haemoconcentration, and a hypercoagulable state.

Keywords: Cerebral Thrombosis, Cerebral Edema, Altitude, Mountaineering, Extreme Cold, Headache
\end{abstract}

Citation: Khan ID. Cerebral venous sinus thrombosis masquerading as high altitude cerebral edema at extreme altitude. Int J Travel Med Glob Health. 2016;4(3):96-98. doi:10.20286/ijtmgh-040306.

\section{Introduction}

Extreme altitude travel has gained popularity globally for adventurous, scientific, and military endeavors. cerebral venous sinus thrombosis (CVST) at extreme altitude is a rare and covert illness requiring immediate intervention. ${ }^{1}$ The annual incidence estimates of CVST are 3-4 cases per million with a female: male preponderance ratio of 1.29:1, commonly affecting in the third and fourth decades. ${ }^{2}$ The reported mortality is $13.8 \%-48 \%$; $12 \%$ of survivors have suffered from long-term neurological sequelae, 59\% from thrombotic episodes, $10 \%$ from seizures, $11 \%$ from severe headaches, and $1 \%$ have become dependent. ${ }^{3}$ Death and severe impairment are more common in ages above 37 years, males, and patients who are comatose, have altered mental status, intracerebral haemorrhage, cerebral deep vein thrombosis, central nervous system infections, and malignancies. ${ }^{4}$ There is a paucity of data on CVST at extreme altitude. CVST may masquerade as high altitude cerebral edema (HACE), both of which may present as headache not relieved by acetaminophen, incoordination, ataxia, altered mentation, diplopia, seizures, coma, and high mortality. ${ }^{5,6}$ However, presentation at extreme altitude can be muted, altered, or overlapping.,

Extreme altitude, defined as an altitude above $5500 \mathrm{~m} / 18000$ $\mathrm{ft}$, imposes extremes of hypoxia, cold, terrain, weather, and logistic problems, all of which influence human health and healthcare under a synergistic interplay. ${ }^{6-8}$ The case being discussed highlights important aspects of a rare presentation of CVST within a few days of ascent which masqueraded as HACE at an extreme altitude of $6700 \mathrm{~m} / 22000 \mathrm{ft}$ in the Karakoram Himalayas.

\section{Case Presentation}

A 38-year-old healthy married male had no problems on ascent from $2740 \mathrm{~m} / 9000 \mathrm{ft}$ to $5790 \mathrm{~m} / 19000 \mathrm{ft}$ through a monitored staged-graded acclimatization schedule on the Karakoram Himalayas in December. After acclimatizing for four more days at $5790 \mathrm{~m} / 19000 \mathrm{ft}$, he ascended to $6700 \mathrm{~m} / 22000 \mathrm{ft}$ in a single day. This ascent was a challenging climb over a 700 $\mathrm{m}$ high ice wall with a 60 to 70 degree incline punctuated by two crevasses. Maneuvering the unrelenting crevassed ice wall with climbing gear and a backpack in winter with the temperature dipping to minus $50^{\circ} \mathrm{C}$, required a prolonged, arduous, and exacting effort.

Twelve hours after reaching the altitude of $6700 \mathrm{~m} / 22000$ $\mathrm{ft}$, the climber complained of mild headache over the frontal region and general discomfort around midnight. A paramedic present at $6700 \mathrm{~m} / 22000 \mathrm{ft}$ reported his condition through a hand-held radio communication device to the medical doctor at $5790 \mathrm{~m} / 19000 \mathrm{ft}$. Preliminary examination revealed a normal temperature, hypertension, tachycardia, and tachypnea. Acute mountain sickness (AMS) was expectedly suspected. Rest at the same altitude, plenty of fluids, acetaminophen 
$500 \mathrm{mg}$, and acetazolamide $250 \mathrm{mg}$ were initiated following which the patient reported improvement in his headache and went to sleep. The next morning he complained of a mild to moderate frontal and central headache, discomfort, and lassitude. There was no change in his vitals from the previous night. He was offered supervised portable altitude chamber (PAC) nursing for one hour along with acetaminophen and acetazolamide. There was transient improvement with rebound headache, tachycardia, tachypnea, and hypertension after a few hours. Severe AMS was suspected and PAC nursing was offered the second time for 2 hours with a 10-minute break in between. By this time, it was afternoon and the weather had deteriorated into complete whiteout followed by heavy snowfall leading to the complete disruption of communication. While the patient was being attended by the paramedic with assistance from fellow climbers, neither could he be monitored by the medical doctor, nor did the possibility for descent or evacuation exist. After the weather cleared and communication was re-established through a hand-held radio device, altered consciousness and altered vitals were reported by the paramedic. HACE was suspected. Immediate descent was planned from $6700 \mathrm{~m} / 22000 \mathrm{ft}$ to $5790 \mathrm{~m} / 19000 \mathrm{ft}$. The descent was exacting as it had to be executed in the dark with limited human assistance over the crevasse-laden ice wall on a 70-degree incline. The patient was considered a lying casualty and was carried in a basket stretcher to the edge of the ice wall from where the stretcher was descended through top belay using static ropes with human assistance on one side to stabilize the stretcher along the decided route on the wall. The two crevasses on the ice-covered mountain slope were having the upper edge higher than the lower making it difficult to manoeuver the patient across it. The basket stretcher was slid carefully over the ladder with belay support from both sides. The descent to the base of the ice wall at $5950 \mathrm{~m} / 19400 \mathrm{ft}$ took three hours. The casualty was carried on snow scooter in a sitting position for $500 \mathrm{~m}$ to $5790 \mathrm{~m} / 19000 \mathrm{ft}$ where the doctor received the patient. He had altered consciousness, feeble pulse and respiration with oxygen saturation $65 \%$. Blood pressure could not be recorded. He was offered passive rewarming: warm crystalloids and dexamethasone $8 \mathrm{mg}$. Oxygen and inotropes were not available. His condition deteriorated further leading to his demise despite aggressive resuscitative efforts. The casualty had no history of thrombophilic disorders, embolic phenomena, blood dyscrasias, collagen vascular diseases, stroke, encephalitis, intracranial abscess, meningitis, subdural empyema, systemic lupus erythematosus, hyperhomocysteinemia, nephrotic syndrome, hepatic cirrhosis, sarcoidosis, chronic inflammatory diseases, otorhinolaryngeal problems, malignancy, exposure to steroids, erythropoietin or heparin, head and neck trauma, or surgery. His body was dispatched by rotor-wing aircraft the next day. Post-mortem investigations revealed superior sagittal sinus thrombosis delineating the development of CVST at extreme altitude.

\section{Discussion}

Headache and discomfort after ascending can be due to altitude illness (AMS, HACE, acute hypoxic cerebral dysfunction/AHCD), CVST, migraine, fatigue, dehydration or hypoglycemia. Fatigue, dehydration, and hypoglycemia can coexist with AMS, HACE, AHCD, and CVST. Altitude illness being the most common should come first in differential diagnoses. AMS and HACE were diagnosed by Lake Louis consensus criteria as there was a recent gain in altitude. ${ }^{6,7}$ AHCD at extreme altitude may be pathophysiologically different from HACE. Migraine at altitude generally presents as headache with focal neurological symptoms. CVST is not only rare, but it is also a diagnostic and therapeutic challenge in extreme altitude. While it may present as a thunderclap headache, abnormal vision, symptoms of stroke, seizures, and focal neurological deficits, the presentation may be altered or oligosymptomatic at extreme altitude. Both HACE and CVST may present with headache as the only symptom, not relieved by acetaminophen as in this case. ${ }^{6,9}$ Altered vitals may point towards an uncompensated physiological state due either to the ascent, the altitude, or the movement of the patient on the mountains.

CVST at extreme altitude can be spontaneous. ${ }^{10}$ Prolonged hypobaric hypoxia and anoxia at extreme altitude can precipitate thrombosis through capillary damage, haematological alteration leading to increased viscosity due to secondary polycythemia, and a hypercoagulable state, especially because of the increased factor VIIa activity and platelet activation. ${ }^{11,12}$ CVST is sometimes associated with stroke, the possibility of which appears remote in this case, although it cannot be excluded. ${ }^{13}$ CVST at altitude has also been described with pre-existing risk factors, which were excluded in this case through a review of the casualty's medical records. CVST can cascade in the setting of polycythemia, haemoconcentration, dehydration, vascular spasms, and cerebral circulatory disturbance produced by comorbid HACE. ${ }^{12}$ The possibility of comorbid CVST and HACE in this patient cannot be conclusively excluded.

Neither diagnostic investigations such as computed tomography-venography, magnetic resonance venography, cerebral angiography or transcranial color-coded duplex sonography, nor pre-emptive etiological investigations regarding coagulation parameters are available at extreme altitude. ${ }^{6,7}$ Death is attributable to herniation caused by mass effect in CVST. CVST has been unnoticed and has been reported at autopsy as in this case. ${ }^{6,14}$ It has also been reported in fatal cases of HACE. ${ }^{15}$

Treatment modalities with anticoagulation, thrombolysis, and mannitol administration are dependent on diagnosis and require monitoring under intensive care due to the risk of hemorrhage into venous infarcts. Immediate treatment with repeated doses of low molecular weight heparin, even if initiated at extreme altitude, may need to be continued for weeks or months at an institutional facility depending upon the extent of the thrombosis. Certain cases of CVST may be associated with prothrombotic states, wherein chronic warfarin therapy and monitoring of prothrombin time and INR is mandated. Therapeutic lumbar puncture and surgical intervention may be helpful. ${ }^{11}$

Considering the inherent high mortality rate associated with this disease, the small window of opportunity for definitive treatment and evacuation, and the unavailability of resources for diagnosis, treatment, and monitoring, a high index of suspicion for CVST is mandated. 


\section{Conclusion}

CVST at extreme altitude is an emergent condition which is likely to develop spontaneously through a cascade of hypobaric hypoxia, haemoconcentration, capillary damage, and a hypercoagulable state. Extreme altitude stressors such as hypoxia, cold, terrain, weather, and logistics are deterministic for diagnosis, management, and prognosis. Astute prudence needs to be exercised at extreme altitude where over-diagnosing and erring on the safe side are likely to be beneficial.

\section{Author Contribution}

The author served as the medical officer at $5790 \mathrm{~m} / 19000 \mathrm{ft}$ and attended the patient during his acclimatization, the monitoring of his ascent, tele-medicine support, executing descent, evacuation, and the overall management of the patient on the icy expanse of an extreme altitude.

\section{Conflict of Interest Disclosures}

No conflict of interest.

\section{Ethical Approval}

The patient consent and ethical approval were covered by the institutional committee.

\section{Funding/Support}

None.

\section{Acknowledgments}

The author would like to acknowledge the referral hospital at the base for the support extended during the management of the case.

\section{References}

1. Basnyat B, Cumbo TA, Edelman R. Acute medical problems in the Himalayas outside the setting of altitude sickness. High Alt Med Biol. 2000;1(3):167-174. doi:10.1089/15270290050144163

2. Einhäupl K, Bousser MG, De Bruijn S, et al. EFNS guideline on the treatment of cerebral venous and sinus thrombosis. Eur J Neurol.
2006;13(6):553-559. doi:10.1111/j.1468-1331.2006.01398.x

3. Ferro J, Lopes M, Rosas M, Ferro M, Fontes J. Long-term prognosis of cerebral vein and dural sinus thrombosis. Cerebrovasc Dis. 2002;13(4):272-278. doi:10.1159/000057855.

4. Ferro JM, Canhão P, Stam J, Bousser MG, Barinagarrementeria F, Investigators I. Prognosis of cerebral vein and dural sinus thrombosis results of the international study on cerebral vein and dural sinus thrombosis (ISCVT). Stroke. 2004;35(3):664-70. doi:10.1161/01.STR.0000117571.76197.26.

5. Hackett $\mathrm{PH}$, Roach RC. High altitude cerebral edema. High Alt Med Biol. 2004;5(2):136-146. doi:10.1089/1527029041352054.

6. Khan ID. Comorbid cerebral and pulmonary edema at 7010 $\mathrm{m} / 23000 \mathrm{ft}$. : an extreme altitude perspective. Bangladesh J Med Sci. $2015 ; 14(1): 87$.

7. Khan ID. Extreme altitude pulmonary oedema (EAPO) in acclimatized soldiers. Med J Armed Forces India. 2012;68(4):339345. doi:10.1016/j.mjafi.2012.04.018.

8. Leshem E, Pandey P, Shlim DR, Hiramatsu K, Sidi Y, Schwartz E. Clinical features of patients with severe altitude illness in Nepal. J Travel Med. 2008;15(5):315-322. doi:10.1111/j.17088305.2008.00229.x.

9. Cumurciuc R, Crassard I, Sarov M, Valade D, Bousser M. Headache as the only neurological sign of cerebral venous thrombosis: a series of 17 cases. J Neurol Neurosurg Psychaitr. 2005;76(8):10841087. doi:10.1136/jnnp.2004.056275.

10. Gambhir R, Anand V, Khatana SS, Bedi V. A Brief Review of High Altitude Thrombosis. Indian J Vasc Endovascular Surg. 2014;1(1):20. doi:10.4103/0972-0820.142362.

11. Gupta RK, Jamjoom AA, Devkota UP. Superior sagittal sinus thrombosis presenting as a continuous headache: a case report and review of the literature. Cases J. 2009;2(1):1. doi:10.1186/17571626-2-9361.

12. Song S, Asaji T, Tanizaki Y, Fujimaki T, Matsutani M, Okeda R. Cerebral thrombosis at altitude: its pathogenesis and the problems of prevention and treatment. Aviat Space Environ Med. 1986;57(1):71-76.

13. Prabhakar A, Aggarwal M, Khurana P, Trehan N. Rare case of cerebral stroke \& venous thrombosis developed during high altitude expedition. Indian J Radiol Imaging. 2006;16(3):313. doi:10.4103/0971-3026.29004.

14. Towbin A. The syndrome of latent cerebral venous thrombosis: its frequency and relation to age and congestive heart failure. Stroke. 1973;4(3):419-430. doi:10.1161/01.STR.4.3.419.

15. Dickinson JG. High altitude cerebral edema: cerebral acute mountain sickness. Semin Respir Crit Care Med. 1983;5(2):151158. doi:10.1055/s-2007-1011445. 